Citation: Lopez, M., Kearney, G. \& Hofstädter, K. (2021). Enhancing Audio Description: Inclusive Cinematic Experiences Through Sound Design. Journal of Audiovisual Translation, 4(1), 157-182.

https://doi.org/10.47476/jat.v4i1.2021. $\underline{154}$

Editor(s): N. Reviers

Received: June 15, 2020

Accepted: June 14, 2021

Published: October 29, 2021

Copyright: (C2021 Lopez, Kearney \& Hofstädter. This is an open access article distributed under the terms of the Creative Commons Attribution License. This allows for unrestricted use, distribution, and reproduction in any medium, provided the original author and source are credited.

Acknowledgement: The Enhancing Audio Description project was funded by the UK Arts and Humanities Research Council (AH/N003713/1).

\section{Enhancing Audio Description: Inclusive Cinematic Experiences Through Sound Design}

\section{Mariana Lopez}

Department of Theatre, Film, Television and Interactive Media, University of York

\section{Gavin Kearney}

Department of Electronic Engineering, University of York

Krisztián Hofstädter ${ }^{\bowtie}$

StoryLab, Anglia Ruskin University

\section{Abstract}

This paper explores the creation of an alternative to traditional Audio Description for visually impaired film and television audiences. The Enhanced Audio Description (EAD) methods utilise sound design as the main vehicle for accessibility and advocate for the integration of accessibility practices to filmmaking workflows. Moreover, this integrated strategy results in an organic form of accessibility that can cater for both visually impaired and sighted audiences, championing inclusive cinematic experiences. The present article reflects on the discussions held during focus groups in which mixed audiences of visually impaired and sighted people watched the same film, with the same EAD soundtrack over headphones. The discussions highlight the potential of the format as an example of universal design and accessible filmmaking, which can be enjoyed regardless of audience's sight condition and can be offered alongside traditional Audio Description $(A D)$ in order to cater for different aesthetic preferences.

Key words: audio description, integrated access, universal design, binaural audio, sound design.

\footnotetext{
$\triangle$ mariana.lopez@york.ac.uk, https://orcid.org/0000-0003-0374-7727

\ gavin.kearney@york.ac.uk, https://orcid.org/0000-0002-0692-236X

${ }^{凶}$ krisztian.hofstadter@aru.ac.uk, https://orcid.org/0000-0002-2974-5028
} 


\section{Introduction}

Traditional Audio Description (AD) consists of an audio track in the third person that provides information on the visual layer of a film or television programme (although occasionally it might also clarify sound elements), providing access to audio-visual media to visually impaired audiences. Although on most occasions this additional audio layer does not overlap with dialogue, it does overlap with other sound elements in the soundtrack, such as music and sound effects (Fryer, 2016; Lopez et al. 2018). Furthermore, AD can be thought of as a one fits all solution, in which the variety of preferences, needs and expectations of audiences are not considered. As a result, end users are left with the option of switching $A D$ on or off, with no access to alternatives, as the different needs resulting from the type of sight loss or personal aesthetic preferences of end users are not catered for (Lopez et al. 2018). In addition to this, AD is an accessibility method that sits outside the creative process, and is only added once a film or television production has been completed (Udo \& Fels 2010; Whitfield \& Fels 2013). Said lack of integration can result in misunderstandings in the creation of the $A D$ track in relation to the plot and characters, as well as, potentially, the creation of an accessible version that is of inferior quality when compared to the production (Romero-Fresco \& Fryer, 2018).

An approach in which accessibility is integrated to the creative process, such as the one proposed by the field of accessible filmmaking (Romero-Fresco, 2019), while also considering the personalisation of experiences (Lopez et al., 2018) and the potential of creative sound design (Lopez et al., 2020a), could offer a solution to these limitations. A future in which end users can select the type of accessibility method, including $A D$, that they would like to access. Thus, addressing the lack of diversity considerations within the field of accessibility and embracing a user-centred approach.

Enhancing Audio Description was a project funded by the UK Arts and Humanities Research Council which sought to minimise the number of verbal descriptions and, as a result, avoid them masking crucial elements in the original soundtrack. Instead, the project favoured the creation of accessible experiences through sound design strategies that can be integrated to the creative and technical workflows involved in film and television productions, and which could be offered as an alternative to traditional AD. The project focused on the combination of three main methods for accessibility purposes, which are referred to as Enhanced Audio Description (EAD) (Lopez et al., 2018, 2020a).

The first method is the addition of sound effects to provide information on actions, elicit the use of establishing shots, convey abstract scenes as well as indicate time, place, and the presence of characters. The second method is the use of binaural audio to allow the conveyance of the position of characters and objects portrayed on the screen. Finally, the use of the l-voice (or first-person narration) (Chion, 1999) to portray aspects of the story that cannot be conveyed through sound effects or spatialisation, such as feelings, gestures, colours as well as certain actions. 
Figure 1.

The Enhanced Audio Description (EAD) methods, bringing together sound effects, binaural audio and the I-voice.

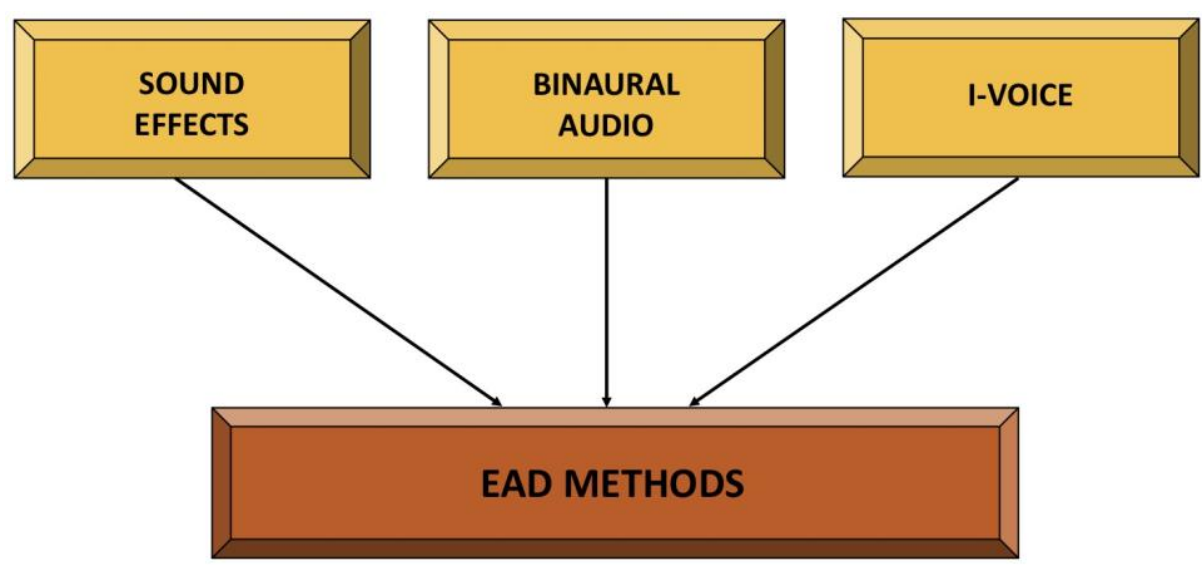

The following sections explore the discussions that took place as part of focus groups and interconnects them with theoretical research on universal design and integrated access, as well as filmmaking and sound design. In section 2 the methodology applied in the case study Pearl (Palumbo, 2015) and in the focus group work is outlined. This is followed by section 3, which reflects on how the EAD methods are an example of universal design practices. Section 4 focuses on EAD methods as a type of integrated access, while highlighting how this might have resulted in the film being perceived as a radio play rather than as a cinematic experience. Section 5 moves on to discuss participants' feedback on the use of sound effects, audio spatialisation and first-person narration, before exploring participants' reflections on innovation and the cost of accessibility in section 6 . Although wide in scope, the present paper explores how the very experience of the EAD example prompted a wider discussion on accessibility and its integration to audio-visual media.

\section{Methodology}

The methodological approach applied to this project will be reflected on, firstly, in relation to our case study, the short film Pearl (Palumbo, 2015), and the strategies employed to incorporate the EAD methods. Secondly, the approach taken to focus group work will be discussed, particularly in relation to how the data collection stage sought to explore the potential of the new EAD methods to foster social inclusion.

\subsection{Case Study}

The effectiveness of the EAD methods was explored through a case study, the short film Pearl (Palumbo, 2015). The film focuses on a young girl called Margaret, who has the ability to produce pearls. The cinematography works on darkness and shadows and the production design looks to 
generate ambiguity by blending Victorian Gothic horror elements with contemporary ones. The film was chosen as a case study due to the research team's initial involvement as advisors to the production as well as its unusual storyline, that would test the effectiveness of the EAD methods to provide information on the story as well as engage audiences in an unpredictable drama.

Some examples of the first method, that is, the use of additional sound effects for accessibility, include the incorporation of bed spring sounds to indicate that the main character is sitting on the bed; the use of ambience tracks of the sea together with either seagulls or crickets, to indicate the main location of the film and whether it is day or night-time; the conveyance of hallucination scenes through the use of whispered voices and sound processing; the addition of breathing sounds from the characters to indicate their presence; and the use of soundmarks (Schafer, 1994) to indicate specific rooms in the house, such as a grandfather clock to indicate the presence of the characters in the living room.

The second method was the use of binaural audio, which refers to the presentation of audio over headphones that carry the same spatial information as sound sources experienced in real life, and in which audio is perceived as external to the headphones, and as if present in the real world. Within the EAD methods, binaural audio was used to pan the dialogue and sound effects to match the position of characters and objects on screen. In this manner, it is possible to indicate that a character is moving, for example, from left to right and maybe, front to back, without requiring a verbal description. In terms of object positioning, this technique allowed for conveying the layout of the rooms, without needing a verbal commentary, for example, by panning the fireplace to the left and the door to the right surround of the listener.

Finally, the I-voice or first-person narration allowed for the conveyance of emotions as well as elements deemed difficult to communicate with sound effects or audio spatialisation. Figure 2 shows an example of how the I-voice was utilised in the opening sequence of Pearl, through a tiled image including 4 screenshots. The upper left image shows the close up of a bucket being held by two hands, the 1 -voice reads "The nurse brings the silver bucket and gets me ready." The upper right image shows a wide shot of a bedroom with someone sitting on the bed, there is a woman to the left and someone approaching the bed on the right, the text says "Mother comes in". This is followed by a close up of a woman, with the l-voice explaining "She gets the oxygen mask." The final screenshot on the lower right, shows an extreme close up of someone's upper back and reads, "as something moves under my skin." 
Figure 2.

Example of the use of first-person narration (I-voice) in a section of the film Pearl. (CUniversity of York.

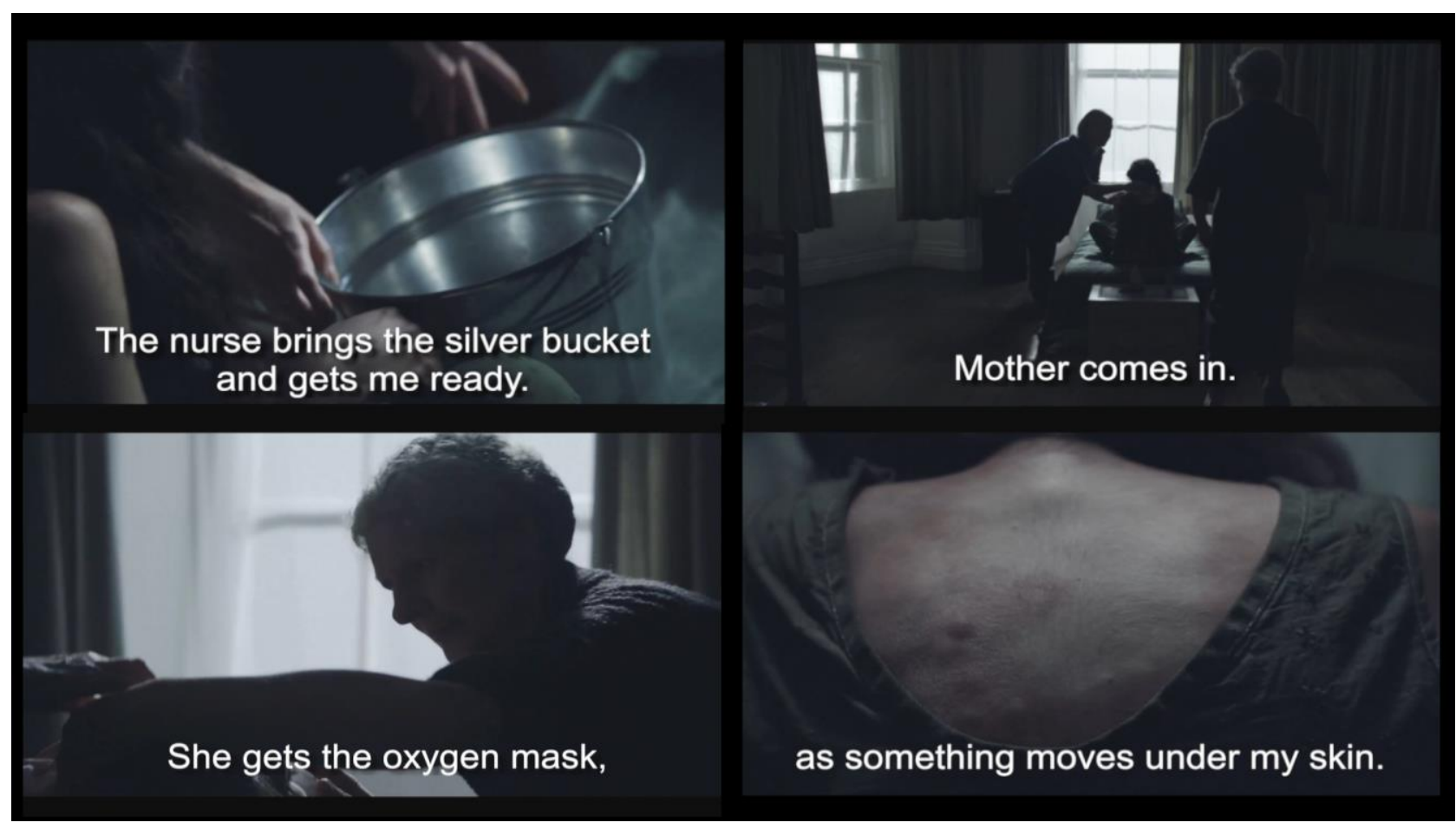

A full analysis of the redesign of Pearl's soundtrack can be found in a previous article by the authors, which also explores the results of a series of interviews with 50 visually impaired participants (Lopez et al., 2020a). The analysis of said interviews demonstrated that the EAD soundtrack performed as well as traditional $A D$ in terms of the information provided and the enjoyment experienced, and was just as accessible, demonstrating the potential of the format to be offered as an alternative to traditional $A D$ and cater for different aesthetic preferences among audiences (Lopez et al., 2020a).

The section below explores an additional stage of data collection which investigated the potential of the EAD methods to foster social inclusion when considering visually impaired and sighted audiences experiencing the same soundtrack.

\subsection{Exploring social inclusion through sound design}

In addition to exploring the effectiveness of the EAD methods (Lopez et al., 2020a), the research team was also keen to investigate whether this accessibility strategy could encourage shared experiences between visually impaired and sighted audiences, and contribute towards greater societal inclusion. In order to gather information on whether Pearl's EAD soundtrack could encourage such experiences, the research team organised three focus groups in 2017 in the UK, one in Cambridge and another two in York, with a total of 63 participants. Details on the demographic composition of the focus 
groups can be seen in Tables 1-4. Participants were diverse in terms of gender and age groups, including the 15-24 age range, and up to 65+. In terms of sight condition, the groups included 36 $53 \%$ of sighted participants, and visually impaired participants included a variety of sight conditions (blind, blind with residual vision and partially sighted). When considering their experience in the use of $A D$, it ranged from never having experienced $A D$ or not knowing what it was (this was the case of some sighted participants), to being regular $A D$ users.

Table 1.

Age ranges and gender of research participants

\begin{tabular}{cccccccccc}
\hline & & \multicolumn{4}{c}{ Age } & \multicolumn{3}{c}{ Gender*** } \\
\cline { 3 - 10 } City & Date & $15-24$ & $25-34$ & $35-44$ & $45-54$ & $55-64$ & $65+$ & Female & Male \\
\hline York* & $26 / 10 / 2017$ & $21 \%$ & $5 \%$ & $5 \%$ & $16 \%$ & $32 \%$ & $21 \%$ & $42 \%$ & $58 \%$
\end{tabular}

$\begin{array}{cccccccccc}\text { Cambridge* } & 1 / 11 / 2017 & 5 \% & 21 \% & 11 \% & 11 \% & 37 \% & 16 \% & 42 \% & 58 \% \\ \text { York** } & 9 / 11 / 2017 & 16 \% & 8 \% & 4 \% & 24 \% & 40 \% & 8 \% & 48 \% & 52 \%\end{array}$

\section{* 19 participants}

** 25 participants

*** Gender demographics were captured through an open comments box to move away from the binary of 'Female/Male.' We have only included the answers entered in the forms.

Table 2.

Sight condition of research participants

\begin{tabular}{cccccc}
\hline \multirow{2}{*}{ City } & Date & Blind & $\begin{array}{c}\text { Blind with } \\
\text { Residual } \\
\text { Vision }\end{array}$ & $\begin{array}{c}\text { Partially } \\
\text { Sighted }\end{array}$ & Sighted \\
\cline { 3 - 6 } & & & $21 \%$ & $11 \%$ & $53 \%$ \\
York & $26 / 11 / 2017$ & $11 \%$ & $16 \%$ & $11 \%$ & $42 \%$ \\
York & $1 / 11 / 2017$ & $32 \%$ & $8 \%$ & $20 \%$ & $36 \%$ \\
\hline
\end{tabular}


Table 3.

Sight condition of research participants with sight loss

\begin{tabular}{cccc}
\hline & & \multicolumn{2}{c}{ Sight Loss } \\
\cline { 3 - 4 } City & Date & Congenital & Acquired \\
\hline York & $26 / 10 / 2017$ & $88 \%$ & $12 \%$ \\
Cambridge & $1 / 11 / 2017$ & $36 \%$ & $64 \%$ \\
York & $9 / 11 / 2017$ & $63 \%$ & $63 \%$ \\
\hline
\end{tabular}

Table 4.

Experience of $A D$ of research participants

\begin{tabular}{cccccc}
\hline \multirow{2}{*}{ City } & Date & Users of AD & $\begin{array}{c}\text { Have a } \\
\text { friend/family } \\
\text { that uses AD }\end{array}$ & $\begin{array}{c}\text { Never } \\
\text { experienced } \\
\text { it }\end{array}$ & $\begin{array}{c}\text { Don't know } \\
\text { what it is }\end{array}$ \\
\hline York & $26 / 11 / 2017$ & $42 \%$ & $42 \%$ & $16 \%$ & $0 \%$ \\
Cambridge & $1 / 11 / 2017$ & $58 \%$ & $42 \%$ & $0 \%$ & $0 \%$ \\
York & $9 / 11 / 2017$ & $64 \%$ & $12 \%$ & $20 \%$ & $4 \%$ \\
\hline
\end{tabular}

Two screening rooms were used to showcase the film, one located at University of York and the other at Anglia Ruskin University in Cambridge. The audio was played to everyone through a combination of wired (Superlux HD-681) and wireless headphones (Over-Ear Bob Silent Disco). All participants wore headphones and were asked to relax and watch the film as if they were at the cinema. Once the film had been screened the focus group leader, which remained constant throughout the focus groups, initiated the discussion. Although all groups were asked the same questions, the discussions were kept open to encourage participants to input on other areas of interest.

\section{EAD and Universal Design Principles}

Universal Design strategies are centred in the desire to create products and environments that are free of barriers, accessible to everyone, by considering accessibility to be integral to the design process (Story et al., 1998). The start of the Universal Design movement was prompted by noticing that designing accessible environments benefitted not just the intended end users, but a much larger number of people (Story et al., 1998). Furthermore, integrating accessibility to the start of the design process was proven to result in more aesthetically pleasing outcomes at a lower cost and could be marketed to a greater percentage of the population (Story et al., 1998). As will be seen in the following sections, the EAD methods can be associated with three of the principles of Universal Design: "Equitable Use"; "Flexibility in Use" and "Simple and Intuitive Use" (Story et al., 1998). 


\subsection{Equitable Use}

"Equitable Use" (Story et al., 1998) refers to the design itself being fit for purpose for a variety of people. The creation of the EAD soundtrack for Pearl explored the design of a version of the film that was accessible, appealing and enjoyable to everyone regardless of their sight condition. Furthermore, by exploring the use of headphones for binaural audio for all audience members, it removed the potential segregation generated by the fact that in traditional AD only visually impaired audience members wear headphones in the cinema (see section 5.2.2 for a discussion on headphone use).

One of the visually impaired participants in the project focus groups mentioned:

I loved the fact that it's potentially much more inclusive, because normally you have the normal version and then the special blind version, and it all goes to just reinforce this thing that we live in this separate world from everyone else and we live in the same one. So, if ever we can encourage people who create things to think about using sound, binaural, stereo, audio techniques as a way of conveying information, feeling, mood, etc., as well as just visual, I think that is good and it enhances it for everybody.

Sighted participants also expressed how they benefitted from the enhanced soundtrack:

I would have missed out hugely without the speech and the way everything was introduced, it would have been quite strange to have tried to get hold of the story just through the imagery...the actual sound was imperative and hugely helpful as a sighted person.

"Equitable Use" is more likely to be achieved through a consideration of audiences' needs and expectations through a process of consultation, which should be integral to the creation of the products themselves. In this regard, di Giovanni (2018, p. 191) reminds designers to bear in mind the "main" and "secondary" beneficiaries of $A D$, as well as to acknowledge diversity among visually impaired users. Furthermore, di Giovanni (2018) encourages providers of services to consider not just engaging visually impaired people by asking for feedback on products or experiences, but to also consider engaging them in the creation of the AD tracks themselves. Similarly, Kleege (2018) reflects on such collaborations in relation to art gallery/museum tours for blind visitors. Kleege (2018) argues that blind visitors should not be regarded as passive audiences, but that galleries should engage in active conversations and sharing of knowledge, by acknowledging, for example, their experience of tactility. Likewise, the Enhancing Audio Description project engaged visually impaired audiences throughout the planning and creative processes, by brainstorming ideas, implementing them and then requesting feedback on what worked and what did not, which will also feed into future projects. 


\subsection{Flexibility in Use}

The Enhancing Audio Description project also looked into the second principle of Universal Design "Flexibility in Use" (Story et al., 1998), which is associated with the need to accommodate a range of preferences and needs of users. Although the accessible soundtrack for Pearl might not have followed this principle within itself, the Enhancing Audio Description project explored how alternatives to traditional $A D$ could be offered alongside each other, allowing users to choose what suits them best. A film, for example, could then be offered without $A D$, with $A D$ and with $E A D$, allowing the end user to select their preferred choice at home or at the cinema. This availability of choice might, as a result, motivate visually impaired people to visit the cinema more regularly. In a survey conducted in 2016 , the authors found that $33.86 \%$ of visually impaired people surveyed had not attended the cinema in the last 12 months, compared to only $5.5 \%$ of sighted people surveyed, with issues of accessibility discouraging visually impaired people from attending (Lopez et al., 2018). More widely available and varied accessibility formats could help remove this barrier.

\subsection{Simple and Intuitive Use}

The EAD format is also linked to the third principle of Universal Design "Simple and Intuitive Use" (Story et al., 1998), that is, a product that can be widely understood regardless of previous knowledge, language skills or concentration level. In this regard, it was telling that visually impaired participants commented on finding the EAD experience more atmospheric and relaxing than traditional AD:

I think that with what we just heard, it didn't involve quite so much concentration, the Audio Description wasn't that intense, you weren't bombarded so much, sometimes with Audio Description you know if it's too much and too intense it distracts from the film or the play or whatever it is you are seeing.

\section{Subjectivity, Creativity and Integrated Access}

This section explores the differences between traditional practices of objectivity in AD vs. more novel approaches incorporating subjectivity and creativity into accessibility. The latter are then presented in the context of integrated access and how integrated workflows can result in experiences that are truer to universal design tenets. Furthermore, the incorporation of accessibility to creative workflows is also explored in relation to audience's perception of the EAD methods as bearing similarities with radiophonic experiences. 


\subsection{Subjectivity vs. Objectivity in accessible experiences}

Traditional $A D$ guidelines indicate that objectivity and neutrality are key in terms of script and delivery (Fryer, 2016; Rai et al., 2010; Snyder, 2007). However, there has been a recent trend towards questioning objectivity and instead considering accessibility as part of the creative process, requiring the collaboration between creative teams and accessibility experts (Fryer, 2018a-b). Cavallo (2015) puts to question the neutrality of $A D$ and reflects on the tight control the audio describer has on what information is considered relevant, how it is delivered and what audiences should be focusing on. Thompson (2018) also draws attention to the fact that the AD creation process is disassociated from filmmaking, meaning that the $A D$ created might not necessarily represent the artistic vision of the filmmaking team and, as a result, it transforms the product into something different by the mere act of providing the description. Thompson (2018) also highlights that for visually impaired audiences, $A D$ is considered intrinsic to the film, the same as aspects of cinematography and editing, and invites filmmakers to take on a proactive role in the creation of accessible experiences. Similarly, Udo and Fels (2010) highlight the importance of taking a step back from considering the aim of AD as one of equivalence, that is, one in which we attempt to provide an equal experience to that of sighted people; instead, they suggest that entertainment should be at the forefront, which might mean incorporating differences to the 'original' product. Udo and Fels (2010) also refer to the work of the describer as that of an interpreter and they advocate for a method in which film directors have an active role in the creation of AD. Similarly, as will be explored in section 4.2, Romero-Fresco has done extensive research in the field of accessible filmmaking, in which accessibility is incorporated from the start of film projects $(2013,2019)$.

There have been a number of projects that have explored different methods and degrees of subjectivity in $A D$ for film, including work on 'auteur description' (Szarkowska, 2013), which integrates knowledge derived from the film script, interviews with the director and film reviews, hoping to capture the unique marks of the director's work. Walczak and Fryer (2017) have explored Creative Audio Description (CRD) and its impact on the emotional reception of the film as well as the sense of immersion. Naraine, Fels and Whitfield (2018) also found that the incorporation of AD to the creative process as well as its delivery with emotion and intonation matching the source material, was well received by $A D$ users.

The presence of the I-voice (Chion, 1999) or first-person narration (inspired by the work by Fels et al. 2006) in Pearl opened up a discussion on objectivity vs. subjectivity in AD among focus group participants. Participants' reflections ranged from mentioning that the l-voice added an additional interesting dimension to the filmic experience, to suggesting that it took away from audiences' personal interpretations. For example, one of the visually impaired participants felt that the l-voice (which is discussed more thoroughly in section 5) moved away from the objectivity they were expecting: 
One of the things of watching a film if it has good audio description is that it allows you to put your own interpretation to it, whereas what we were listening to...it was very much someone almost interpreting it for you.

Kleege (2018) critiques notions of objectivity in AD explaining that they are based on the illusion that audio-visual media is unmediated and will remain the same regardless of the viewer, and leaves aside the notion that the language chosen by the describer has a number of connotations and associations that do not remain constant. Kleege (2018) also adds that it is the lack of acknowledgement of authorship in $A D$ that is partly responsible for the creation of the illusion of objectivity, as the description is presented as the truth, rather than one possible interpretation of the text.

\subsection{Integrated Access and Accessible Filmmaking}

The topic of subjectivity in $A D$ is closely linked to integrated access. In relation to live productions, Fryer (2018b) refers to Integrated Audio Description, as AD that is considered intrinsic to the production (not an afterthought or an add-on); defies neutrality (that is, it may be subjective or have a significant amount of creative license incorporated into it); it is a collaboration between an accessibility expert and the director of the production; and it is available to everyone, regardless of their sight condition. Furthermore, Fryer (2018b) points out that integrated access demonstrates the commitment of the creators to accessibility and helps raise awareness in wider audiences. Furthermore, Fryer (2018b) mentions how users of accessibility services with integrated access know that the $A D$ has been approved by the director, and might be more willing to access it, as an 'approved' version.

In the field of film, Pablo Romero-Fresco $(2013,2019)$ has done pioneering work on Accessible Filmmaking, a workflow for the creation of films in which accessibility is integrated to the filmmaking process. Akin to Thompson's reflections (2018), AD would be considered key to the film in question rather than an addition at the end of the postproduction process. Romero-Fresco (2019) explains that by introducing accessibility to the filmmaking process the creative aims of the director and the filmmaking team can be maintained, and the creative team can be shown the advantages of being involved in accessibility: 'their' version of the film will reach all audiences. The accessible filmmaking approach does not only provide wider access, it also helps the filmmaking team retain control over their work (Romero-Fresco, 2019). In addition to this, Branson (2018) explores how accessible filmmaking bridges the "Maker-Expert-User Gap", the maker being the filmmaker, the expert being the accessibility expert and the user being the person experiencing the accessible version of a film.

Romero-Fresco and Fryer warn (2018) that an AD track in which the filmmaker has had no input could lead to a lack of relevant narrative information, a failure in establishing the plot points, a misrepresentation of characters and even a product that is inferior in quality to the one intended by the filmmaker, and which ends up being regarded of poor quality by visually impaired audiences due to a failure to create accessible versions that are up to standard. Kleege (2018) also mentions her 
support towards forms of access in which filmmakers, screenwriters and actors work together to provide AD, and Ellis and Kent (2011) support similar notions in relation to online platforms.

\subsection{Filmic vs. Radiophonic Experiences}

One of the recurring and unprompted themes in the focus groups was whether the experience of the EAD soundtrack was analogous to that of a radio play. Such comparison is curious, as the sound design team in charge of the EAD soundtrack drew from conventional film sound design practices, rather than radiophonic creations, in the process of creating the final outcome. However, this is an area that requires reflection as it seems to be closely connected to the fact that the soundtrack presented to end users in the EAD project had its access features fully integrated to the experience, as per universal design practices and integrated access principles. Accessibility was not an add-on but, on the contrary, just as a radiophonic experience, the EAD format was complete in itself without any need for visual elements (Rattigan, 2002). Volunteers were provided with a 'new' experience of accessibility, an experience that, it could be argued, does not sit in the traditional realms of what 'listening' to a film is like, as it is complete in itself, without the need for visuals. It is possible, based on the comments noted below, that visually impaired volunteers felt that it was that completeness of the experience that equated it to a format that does not include visuals, such as radio drama. It is also possible that it is the fact that sound effects are allowed to 'speak' for themselves and that accessibility is integrated seamlessly to the experience, that differentiated it from their regular film experience. This is supported by comments from focus group participants. For example, when asked what elements they identified as pertaining to radio plays, one of the visually impaired participants mentioned:

I think because there's a lot of sound effects in the film which you get on the radio when you are listening to stories and because...it felt like it was telling you a story with the first-person narration...it didn't need any visuals at all...

It is interesting to note how the emphasis on sound effects and the presence of narration were seen as key indicators of similarities to radio plays. Although the presence of the I-voice bears similarities with methods of narration used in radio drama, we attempted to use it sparingly to complement the use of sound effects and spatialisation, rather than as the main driver of the story. The EAD methods work together with the main soundtrack (dialogue, sound effects and music) to provide a full experience for both visually impaired and sighted audiences. Whereas research in radio drama has emphasised the need for contextualising sound effects for audiences through verbal commentary (Crisell, 1994; Rattigan, 2002), which is also considered key in audio description work but can be found patronising by end users (Lopez et al., 2020a), the EAD methods use the full soundtrack to provide context, a method that was also found successful in previous work on 'audio films' (Lopez \& Pauletto, 2009a-b; Lopez, 2015). Furthermore, previous work on 'audio films' demonstrated that contextualising sound effects immediately is not always necessary, that is, a verbal explanation is not always needed (Lopez, 2015). Visually impaired audiences reported that they were willing to accept 
a short period of confusion before a sound effect's full meaning was made clear, and this did not undermine their understanding of the plot (Lopez, 2015). This indicates that a line of I-voice is not always necessary to clarify meaning, and the context of the piece may be sufficient.

For another visually impaired participant, the similarities of EAD to radio plays were a positive, but more thought should be put on reflecting on the amount of description available:

I like the fact that it is like a radio play, however, I do find, if you've ever had a book and they made it into a film, you miss out a lot of detail because in the book they are able to describe the feelings, emotions, smells, everything...and it would have been nice to have facial expressions, etc. and even set the scene.

In this regard, one of the sighted participants mentioned:

I liked the level of audio description in that but I do listen to audio description at home when it's on, but even though I started off thinking this is really good because it isn't a constant bombardment...but then...there wasn't any description of the room or where she was...

It is also worth mentioning that sighted participants did not find the format redundant, that is, they did not feel the sound just replicated the visuals, they felt it created a new, unique experience. True to the principles of universal design and integrated access, the EAD methods looked into creating a unique experience in its own right.

In relation to the reflection on radio vs. filmic experiences, it is of relevance to point out that several participants mentioned the fact that it took a period of familiarisation to realise that they were having an accessible experience, which further supports our argument that it is the format's completeness that equates it to radio drama:

I use audio description at home but it took me a while to think 'where is the audio description?' I'm used to it saying 'so and so walks into the room and does this.' It took me a minute or so to realise it was embedded in the script...it was just for me a bit disconcerting at first but it then became quite pleasant as you went along.

\section{The EAD methods}

This section of the article explores in more detail focus group responses in relation to each of the EAD methods: sound effects, binaural audio and the l-voice or first-person narration.

\section{1 Sound Effects: Addition and Enhancement}

As Crisell (1994) and Fryer (2010) remind us, sound, when used effectively, can stimulate our imagination. However, we do need to be cautious of its potential for multiple interpretations (Crisell, 
1994), as even what we might consider the most self-explanatory sounds, such as bird song, might be open for questioning (for example, where/when is the bird song taking place?) and, according to Crisell (1994), speech is often required to clarify meaning.

This is a key consideration for the EAD methods, in which the addition of sound effects is central to reducing verbal descriptions while still providing visually impaired audiences with an accessible experience. The addition of sound effects as an accessibility strategy was discussed in the focus groups, though it is interesting to note that this sparked less of a discussion than other methods, which is likely an indication that they were perceived as acceptable by focus group members. One of the visually impaired participants mentioned that they particularly enjoyed the environmental sounds such as rain effects, and another discussed how they believed it to be acceptable for sound effects to replace verbal descriptions of actions:

If you could hear the book being turned and the pages being turned, then that would be ok, because you get the idea, because I think we all know what a book sounds like, the pages turning.

A sighted participant mentioned that they enjoyed the heightened sound effects, and that they conveyed meaning not just about actions but also, through the use of reverberation, the characteristics of the spaces in the diegesis. However, it is worth noting that some participants found sound effects unnatural. A possible interpretation of their perception as unnatural, is the fact that they are prominent in the audio mix, compared to regular film mixing practices.

It was also interesting that another sighted participant commented that a highlight for them was the enhanced breathing track added in the EAD version to indicate the presence and emotion of characters:

...the part that I took from it the most was, the breathing and the rhythms of the breathing...I could hear different emotions, different paces, different intensities in the way the characters were breathing which I thought was very interesting and is sometimes lost in regular film and TV.

\subsection{Audio Spatialisation and Headphone Use}

The section below discusses the use of binaural audio as a technique to spatialise sound effects and dialogue, reducing the need for verbal descriptions by indicating the location of sounding objects and characters. Due to the fact that binaural audio requires the use of headphones, we also explore the implications of all audiences (visually impaired and sighted) using headphones to experience a cinematic production. 


\subsubsection{Binaural Audio}

Sound spatialisation was a focal point for focus groups' discussions. A participant mentioned how it was a plus to their experience and to working out movement in the scene and, as a result, character positions in the shots. This perspective was also shared by another visually impaired participant, who expressed that it augmented their experience as well as allowing them to follow voices around the scene more clearly:

...if you are following voices around and you can hear their footsteps and you can hear where they are, actually I think it would help me to follow the plot and who was speaking. It was easy in this one as there were only 4 characters and they got relatively distinctive voices. But actually, for me the spatiality and being actually in the scenes from a distinct perspective helped especially with the water and the mum's voice, at one point it was to the side, and then I knew...that the camera was at a different angle, to me that is making a picture, that is changing pictures...I could just see it, it was really really powerful. I just took a joy in knowing where everything was and immersing myself in it.

Another visually impaired participant highlighted that enjoyment needed to be a key consideration in accessibility processes:

One of the lovely things about this is that audio techniques were used to actually give lots of extra, not just information but, actually fun and pleasure in it, now it's normally the visual stuff that people go for, and actually filmmakers and programme makers actually ignore the potential of audio to spice things up a bit. You might sometimes get a tiny bit of stereo if a car drives across or something but the dialogue is always in mono, and you think, actually guys it wouldn't be that difficult to do that and, then somebody that is listening to the audio will get more fun out of it, because stereo is much more fun than mono.

Other visually impaired participants added that the use of spatialisation meant that certain narrator comments on movement were not necessary as they could follow the actions as characters moved around the rooms, providing a three-dimensional experience. In addition to this, a sighted participant mentioned that they felt the binaural experience meant the acoustic world of the film was replacing that of the screening room, providing audiences with a more engaging experience, an aim that Kerins (2010) mentions as part of surround sound cinematic practices.

However, not everyone enjoyed the binaural rendition. A visually impaired participant mentioned that they found the sound spatialisation and externalisation disconcerting:

There was a point when the girl was coughing, I thought it was my daughter...it could be a little bit disconcerting sometimes when it comes suddenly from one side.

This participant's description points, technically, to the successful implementation of binaural sound. Binaural experiences are characterised partly by the process of externalisation, that is, the sound source is perceived as emanating from a real source in the room (Blauert, 1997). Similarly, another visually impaired participant mentioned: 
I felt the footsteps were distracting because...I was focusing rather on the footsteps going round the room which detracted from the main dialogue.

A further comment from another visually impaired participant on this matter mentioned:

It was interesting the way that the sound was used in terms of panning from one side to the other but some of it sounded...artificial almost.

There are clear benefits therefore to using binaural audio in the context of Enhanced Audio Description, such as increased localisation and externalisation. However, the sound design must be approached with care, as evidenced from these latter quotes. Consideration in particular should be given to the co-location of Foley and dialogue and of potential timbral issues resulting in the use of binaural filters. The latter may be due to the fact that the filters are not tailored to the individual which is why a small number of viewers felt the EAD soundtrack to have an unnatural or 'artificial' sound. Content platforms that support binaural experiences such as YouTube 360 tend to utilise generalised binaural filters that may not match the natural filtering of the head, torso and pinnae of an individual. However, prior work has demonstrated how for a majority of listeners there is a preference for such generalised filters, even on occasion above binaural filters which have been tailored to the individual (Armstrong et. al, 2018).

\subsubsection{Headphone Use}

The application of binaural audio to the accessible soundtrack necessitates headphone reproduction for all audience members, not just visually impaired attendees. Fryer (2018b) mentions that the exclusive use of $A D$ headsets by visually impaired patrons at the theatre can increase feelings of exclusion. A similar finding emerged from the focus groups, with some visually impaired participants commenting that everyone using headphones reduced the anxiety of disturbing sighted audiences around them due to headphone spill (other audience members not using headphones being able to hear the audio coming from the headsets).

One of the visually impaired participants described a past experience at the theatre:

...I've been at the theatre, I've had staff come up, 'can you turn your audio description down?' But the music is loud so I need it up loud, so people just need to get on with it, but unfortunately you can't do that because you need to respect other people but at the end of the day they need to respect that you can't see...

A system in which everyone is encouraged to experience the film through the same audio reproduction system eliminates the friction between the needs of sighted and visually impaired audiences, which is reflected in the quote. This was also echoed by a sighted participant, that reflected on their experience accompanying their visually impaired partner to the Opera: 
We've used the Audio Description for the Opera. The first time I did wear headphones and it was ok and the second time I didn't and it was quite annoying as a sighted person sitting next to somebody or people around me wearing headphones and I could just hear that noise, and it could be quite irritating, that didn't happen today because we all had them on...

In terms of improving the experience of sighted family members, one volunteer commented that experiencing the same as her partner meant she could enjoy the film and stop worrying, as she knew her husband was getting the information he needed. Other sighted participants also commented that they felt that everyone experiencing the film in the same way, increased the sense of 'sharing', just the same as when people are wearing 3D glasses. Another participant also felt that the fact that they were using headphones helped increase engagement with the film, probably due to there being fewer distractions from within the screening room.

The research team acknowledges the potential limitations of headphone use, for example, in shared experiences in the home environment. Therefore, the next stage of the project will be looking at transferring what was learnt from our studies on accessibility and binaural audio, to the field of loudspeaker-based reproduction systems.

\subsection{I-Voice or First-person narration}

The use of the I-voice (Chion, 1999) or first-person narration was discussed extensively by both visually impaired and sighted participants. There was an acknowledgement among visually impaired participants that the presence of the I-voice meant the experience was different to traditional audio description and with it came the need to adapt and familiarise themselves with the format. One of the participants commented:

It fascinated me how I could tell everything that was happening without audio description...the girl was describing everything, I could understand what was happening...

It was also acknowledged as a more artistic take on accessibility and one that belonged to the field of integrated access, and which could also result in a more widespread use of accessibility methods in mainstream productions. Moreover, participants mentioned that an integrated approach meant that usual issues with $A D$ overlapping key elements of the soundtrack was no longer a problem and redundant information was avoided:

I thought it was really good because there wasn't any overlapping or anything, sometimes with Audio Description, the describer would talk over someone else talking, you get what's happening but you don't get enough of the dialogue as well so you might miss key points, there was a lot of description, but it was a balance, sometimes they can give a lot, but a lot of it can be a bit pointless, they might say 'oh she talks on the phone' but you can clearly tell that they are talking on the phone so you don't need it, so it was a lot but not too much.

There were concerns by both visually impaired and sighted participants as to whether the effectiveness of the I-voice was limited to short films with few characters, and whether its use in full 
length films with larger casts would lead to a need to change from one perspective to the other, causing confusion. A topic that the research team will be exploring in future instances.

It is also worth acknowledging in this regard that both the example shown in the focus groups, Pearl, and the short film Shelf Life (Balla, 2018; Lopez et al., 2020b) which authors worked on subsequently, constitute examples of short character-focused dramas with small casts (4 characters in the case of Pearl and 3 for Shelf Life). These characteristics facilitated the use of the first-person as there was a clear character through which the story was told. An upcoming stage of this project will explore how first-person narration could be used for productions with larger ensembles and with shifting perspectives, while also exploring a variety of genres.

The use of the I-voice also sparked a conversation as to the need for engaging and good quality performances of $A D$, with the l-voice considered as a way to ensure a good quality rendition of the $A D$ script as it would be recorded by the main actor of the film. One of the visually impaired participants mentioned how the monotony of $A D$ voices sometimes put her off watching television or films. This was further supported by a sighted participant that often watches AD with a family member. Her comment similarly pointed out that the use of monotonous voices for AD meant that she often got bored, and that there would be potential for using more experienced actors that could deliver a more engaging experience. Adding to this, another visually impaired participant mentioned that she felt $A D$ actors were generally good but that in her opinion problems of monotony came about when describing very visual films:

For a quite protracted length of time you are just listening to one voice. I understand why they don't put a lot of emotion into it. They are there to describe, not to become part of the action but I do fall asleep on occasion.

Regarding performance in AD, Kleege (2018) mentions, with a fair amount of frustration, how guidelines do not acknowledge the need to match the describer's voice to the content of the film in terms of genre or conveyed emotion, instead opting for trying to simulate the presence of a nonjudgemental companion that is unaffected by the content of the film. Similarly, Fryer (2019) mentions the importance of audio describer's vocal skills, including delivery, pointing out that delivery should match the scene being described, to avoid frustrating audiences. A study by Fryer and Freeman (2014) also demonstrated the key role of prosody to enable emotions to be inferred from AD. Fernández, Martínez and Núñez (2015) have also discussed the importance of the describer's voice being "mood congruent" (2015, p. 81) in relation to the scene being described. Their research showed that mood-congruent descriptions were more successful in conveying the emotions in the scene and allowing visually impaired audiences to anticipate the plot and the intentions of the characters, as well as resulting in a perception of the audio description as being of a greater quality, when compared to the same example using a non-mood-congruent voice.

Also linked to the I-voice was a discussion on how much detail end users are expecting, and how much of this is down to personal preference. This is an aspect of importance to EAD because its format does not rely on the spoken word entirely, it also relies on sound effects and spatialisation to 
provide information, and replace descriptions. For example, focus groups discussed whether facial expressions, costumes and sets needed describing:

One thing I missed a little bit...there wasn't a lot of colour painted with it, there wasn't a lot of scenery, about what exactly was in the room, anything about clothing...or facial expressions... just felt it lacked a little bit about what was in the room, or a little bit about the scenery around them.

Another visually impaired participant added that the need for such descriptions is often film dependent, while another participant felt that the sparse sentences regarding the house in the film were enough to fill in the gaps. Opinions were, as expected, mixed, from participants that considered sparse verbal commentary to be enough, to those that felt they missed the more verbose aspects of $A D$ and those that felt that a middle point could be reached.

In addition to this, another visually impaired participant mentioned that they would be interested in watching films and TV with EAD but it very much depends on the taste of the individual:

...it's the difference between Reader, I married him and they all lived happily ever after. It's a different approach, it's first-person, or each of them being first-person, as opposed to pure action and interpreting from what is visual, it's a different film.

A sighted participant mentioned how the added I-voice gave the film a new, more interesting dimension, and positively affected the pacing of the film:

I really really enjoyed it, I think that this type of narration lends itself to film and if there were more films like this I would be interested in watching them. I liked how personable the story became, I thought it really lent itself to the pacing of the film, I was imagining the film if it didn't have the narration on top of it and I think it could have had the tendency to be a lot slower, it kind of sped up the story which made it a lot better in my view.

One of the sighted focus group participants mentioned that the I-voice enhanced the drama and worked as a self-reflection device, but was not always sure what was part of the description and what was not. In response to this, one of the visually impaired participants mentioned that that was likely to be a problem only for sighted people. From a research perspective, one could also argue that the fact that they are not easily differentiated means they complement each other to form a seamless whole. It is worth stating that the l-voice was enhanced with the use of some reverberation to differentiate it from the dialogue. A relevant area of research is one in which the level of reverberation needed to convey that effect is tested and discussed, in order to determine the amount and type of reverberation needed to differentiate the type of audio stream more effectively, as well as the ranges acceptable to audiences.

Sighted participants mentioned enjoying the level of intimacy and involvement provided by the firstperson narration, and that it was engaging and would encourage them to watch this form of accessibility at the cinema. There were also mentions of sighted participants not even noticing it was an accessible version, meaning it was not intrusive and they welcomed this experience compared to 
traditional AD. However, they also mentioned that the I-voice added to the story rather than just covering what was in the visuals and how certain aspects were ambivalent in terms of plot and characters. It is worth noting that the aspects mentioned, such as the age of the character, were purposefully ambivalent both visually and sonically, and the accessibility layer was not meant to clarify those points, if something was ambiguous in the film, the approach was to retain that ambiguity in the accessible version.

There were also discussions among sighted participants as to whether more detailed descriptions as part of the l-voice were needed, and differing opinions as to what those descriptions should be. However, it is always important to exercise caution as to what is described as, when something is explicitly 'said' in a description, it is possible for it to become the focus point for visually impaired audiences even when it is not the intended focal point of the film, an effect discussed by the authors in a previous article (Lopez et al., 2020a). On this note, Kleege (2018) refers to how certain gestures when described, gain more importance than they would have for a sighted viewer as the act of mentioning them makes them gain prominence.

One of the visually impaired participants highlighted that they felt there was an appropriate balance between the I-voice and the musical elements, and highlighted the importance of musical elements when working on accessibility:

...background music, in this...was quite subtle, it was there to enhance the emotion...If you think of some blockbuster movie...and an AD person trying to shout over the music or alternatively having to dim the music right down for the benefit of people who cannot see, which will lose one element, the music is significantly important otherwise it wouldn't be there...

This is of the utmost importance for the Enhancing Audio Description project which, by incorporating accessibility to the production and postproduction workflows in filmmaking, champions the creation of a specially crafted mix, in which balance among different sound elements is key to the success of the end product. Similarly, Fryer (2010) highlights the need for audio describers to bear in mind that for users of $A D$, the experience of the film is an aural one in which the original soundtrack and the $A D$ are meshed together, so an understanding of the use of different soundtrack elements in the film needs to be reflected on in order to produce a positive experience.

\section{Preferred Formats, Innovation and the Cost of Accessibility}

The focus group discussions held as part of the Enhancing Audio Description project inevitably opened up debates on different formats of accessibility and their appeal to end users. Participants reflected on how EAD would compare, in terms of their preferences, to traditional AD. During discussions it became evident that their choice would be linked to a number of factors. Participants mentioned that they felt it would be dependent on the source material, films of a more intimate nature with fewer characters would be better suited to EAD than films with larger casts, as the latter 
would introduce the complexity of a large number of dialogue voices that would need to be identified, plus the I-voice or I-voices.

Similar discussions as those reported above, in terms of need for familiarisation and its similarity to radio drama, resurfaced when discussing preferences, with one of the participants noting that they would rather stick with what they already know and another mentioning that EAD did not feel like experiencing a film.

Ideas of social interaction dependent on the type of audio description experienced also surfaced as a topic of conversation. One of the sighted participants mentioned:

As a person who is married to a visually impaired person, before his eyes got bad we used to go to the theatre a lot and to the cinema but, as it's got worse... we don't go as much now, so it's restricting not only him but me as well cause I won't go without him. I think it would help and it would help me as well. I'm sure lots of couples are very similar, it would definitely help.

Innovation and the access to more than one format of accessibility, in this case traditional AD and $E A D$, opened up conversations on the cost of accessibility measures. Universal Design principles recognise the economic factors involved in creating accessible products and guidelines acknowledge that if a design can benefit a wide range of audiences (including disabled audiences as well as other end users that had not been anticipated) then it is more likely to be in demand (Story et al., 1998). One of the focus group participants expressed the importance of education in increasing provision:

Things like whether it is very expensive to do audio description or not is all a question as to how people think about it, there was a time when, the idea of disabled toilets first came in, and there was a massive fuss, about how expensive it would be, and how difficult and where would you fit them in and there's no room, and everything and now if you design a building and, if you said you are not going to put an accessible toilet in people would think you are mad, also my bank goes to the massive expense of providing me with a braille bank statement, I don't have to pay anything for it because they stopped thinking about it as something different and special. That's why I'm so keen about this idea of inclusion, because if people think differently about audio, then actually the cost becomes invisible and just gets counted in.

This is a powerful statement that encapsulates some of the ideas behind the Enhancing Audio Description project and its championing of integrated access. The integration of EAD as crucial to current film and television workflows encourages creativity for the filmmaking team (an effect experienced by the sound designers of this project as well as anecdotally recounted by others), while also increasing the reach of the end product, which can benefit visually impaired audiences as well as others who might enjoy the format.

Udo and Fels (2010) reflect on $A D$ as a cost service, that is, a feature that has a cost but does not necessarily bring with it additional revenue. As a result, there are no financial incentives for broadcasters to explore better quality AD or to provide innovative methods of accessibility. Similarly, Romero-Fresco (2019) invites reflection on the advantages of considering the audiences that require 
accessibility services together with those requiring translated versions. If they are considered as a combined market they constitute more than $50 \%$ of most films' revenue (Romero-Fresco, 2019), they are no longer minority audiences and this might have the positive outcome of avoiding accessibility being side-lined and instead ensuring that it is at the centre of filmmaking. Integrating accessibility to the filmmaking process would only cost a very small percentage of a film's budget (Romero-Fresco, 2019; Romero-Fresco \& Fryer, 2018).

\section{Discussion and Conclusion}

The Enhancing Audio Description project explored the creation of a format of accessibility for film and television for visually impaired audiences that can be offered alongside traditional Audio Description, allowing end users to choose what format of accessibility they would like to experience. In this new EAD format, verbal descriptions are minimised, and sound design is used as the main vehicle for accessibility, through a combination of additional sound effects, binaural audio and firstperson narration. At the core of the project was the desire to create inclusive experiences which could be shared regardless of sight condition, by embracing notions of universal design and integrated access.

In section 4, the present article explored the connection between the EAD format and traditional and experimental practices in relation to tenets of objectivity vs. subjectivity, and notions of creativity and integrated access. Furthermore, the authors engaged with the opinions of mixed groups of visually impaired and sighted participants to explore the potential of the format from an end user standpoint. Such opinions were captured through focus groups that followed the screening of a short film with a specially designed soundtrack following the EAD methods, and which was experienced through headphones by all participants.

The EAD format was shown to be successful in gaining acceptance from both visually impaired and sighted audiences, although, as anticipated, differing opinions were expressed. It is telling that one of the sighted participants mentioned how they had forgotten mid-way through that they were watching something with an accessibility layer:

I thought that was great. Because the audio description was integrated to the film. It didn't feel like I was watching something with audio description...

A statement which was supported by another sighted participant:

As a sighted person who has never seen any or very little audio description, this film didn't bother me at all, so it was good to have this amount of audio for me...it did add something to my experience...

These are telling accounts that point towards EAD having the potential of being a widely accepted format, which might, in turn, lead to a greater provision and, as a result, more availability and better quality of accessibility for visually impaired audiences. 
Headphone use by all audience members, rather than just visually impaired patrons, was shown to be conducive to a more inclusive and relaxed atmosphere, as visually impaired audiences no longer needed to worry about receiving negative comments by others or feeling segregated, and sighted people accompanying friends/family were confident that everyone was getting a satisfactory experience.

It was also interesting to reflect on the groups' discussions on whether the EAD experience was equivalent to that of listening to a radio drama, a discussion that pointed towards the need for familiarisation with the new format as well as the fact that the completeness itself of the EAD methods might have led to them being perceived as un-cinematic, an area that requires further research.

EAD methods were also perceived by some participants as having the potential to provide a better quality of performance, by having the first-person narration delivered by the main actor/s. Furthermore, the integration of accessibility to the filmmaking process was also deemed successful in ensuring an appropriate balance of levels among the different elements of the sound mix, although some participants felt the enhancement of sound effects felt unnatural. It is also of importance to mention that some missed the more detailed descriptions on film sets and costumes, and felt those preferences were not catered for. However, the research team believes that the EAD version being offered alongside traditional AD would allow for audiences to choose what fits their aesthetic preferences best, being able to switch from one version to the other when, for example, watching broadcast material.

It is worth noting that the additional sound effects sparked fewer discussions, possibly a sign that they were well integrated to the accessible track and were found acceptable by most participants, with some mentioning their aptitude to reduce verbal descriptions and that the breathing tracks were particularly beneficial to the conveyance of action and emotion.

Audio spatialisation was welcomed by the majority of visually impaired and sighted participants as a method suitable for following characters around the scene, reducing the need for verbal descriptions, and incorporating more cinematic aspects to the soundtrack. Furthermore, it was perceived as a positive addition as it was not just about providing information but also the "joy" of listening to the changes. However, it is worth noting that some found binaural audio and its externalisation effect distracting.

The Enhancing Audio Description project offers to the accessibility sector a new paradigm in the creation of accessible experiences for film and television, one that embraces the potential of sound design to create an organic piece in which accessibility is integrated, rather than an additional layer. By designing such works, the research team provides a vehicle for social inclusion by making cinematic experiences, shared accessible experiences, in which immersing oneself in the story is at the centre. 


\section{Acknowledgements}

The authors specially thank all the focus group participants for their feedback. This project would not have been possible without their input. We are also very grateful to the support provided by our Project Advisory Panel, which included Howard Bargroff, Jerry Gilbert, Lisa Holdsworth, Elfed Howells, Sonali Rai, Jez Watts, John Whiston, and Warren Wilson.

\section{Ethics}

The research reflected on in this article received approval from the Ethics Committee of the Department of Theatre, Film, Television and Interactive Media, University of York.

\section{References}

Armstrong, C., Thresh, L., Murphy, D., \& Kearney, G. (2018). A perceptual evaluation of individual and non-individual HRTFs: A case study of the SADIE II database. Applied Sciences, 8 (11), 2029, 1-21. https://doi.org/10.3390/app8112029

Balla, G. (Director). (2018). Shelf Life [Film]. University of York.

Blauert, J. (1997). Spatial hearing: the psychophysics of human sound localization. Massachusetts: MIT press.

Branson, J. (2018). Bridging the Maker-User Gap: The Case of the Italian Short Film Acquario. Conference Proceedings of Understanding Media Accessibility Quality, Universitat Autònoma de Barcelona, Spain. Available at:

http://pagines.uab.cat/umaq/sites/pagines.uab.cat.umaq/files/UMAQ files/conference/uma q conference book of abstracts final.pdf

Cavallo, A. (2015). Seeing the Word, Hearing the Image: The Artistic Possibilities of Audio Description in Theatrical Performance. Research in Drama Education: The Journal of Applied Theatre and Performance, 20 (1), 125-134. https://doi.org/10.1080/13569783.2014.983892

Chion, M. (1999). The Voice in Cinema. New York: Columbia University Press.

Crisell, A. (1994). Understanding Radio (2 ${ }^{\text {nd }}$ edition). Oxon: Routledge.

Di Giovanni, E. (2018). Audio description for live performances and audience participation. The Journal of Specialised Translation, 29, 189-211.

Ellis, K. \& Kent, M. (2011). Disability and New Media. Oxon: Routledge.

Fels, Deborah I., Udo, J.P., Ting, P., Diamond, J.E. \& Diamond, J.I. (2006). Odd Job Jack Described: a Universal Design Approach to Described Video. Universal Access in the Information Society, 5, 73-81. https://doi.org/10.1007/s10209-006-0025-0

Fernández E.I., Martínez S.M. \& Núñez A.J.C. (2015). Cross-fertilization between Reception Studies in Audio Description and Interpreting Quality Assessment: The Role of the Describer's Voice. In R.B. Piñero and J.D. Cintas (Eds.), Audiovisual Translation in a Global Context. Palgrave Studies in Translating and Interpreting. London: Palgrave Macmillan (pp. 72-95). https://doi.org/10.1057/9781137552891 5

Fryer, L. (2010). Audio description as audio drama - a practitioner's point of view. Perspectives, 18 (3), 205-213. https://doi.org/10.1080/0907676X.2010.485681

Fryer, L. (2016). An Introduction to Audio Description: A Practical Guide. London: Routledge. 
Fryer, L. (2018a). The Independent Audio Describer is Dead: Long Live audio description! Journal of Audiovisual Translation, 1 (1), 170-186. https://doi.org/10.47476/jat.v1i1.52

Fryer, L. (2018b). Staging the Audio Describer: An Exploration of Integrated Audio Description. Disability Studies Quarterly, 38 (3).

Fryer, L. (2019). Quality Assessment in Audio Description: Lessons Learnt from Interpreting. In E. Huertas-Barros, S. Vandepitte and E. Iglesias-Fernández (Eds.), Quality Assurance and Assessment Practice in Translation and Interpreting (pp. 155-177). IGI Global.

Fryer, L. \& Freeman, J. (2014). Can you feel what I'm saying? The impact of verbal information on emotion elicitation and presence in people with a visual impairment. Proceedings of the International Society for Presence Research, 99-107.

Kerins, M. (2010). Beyond Dolby (Stereo): Cinema in the Digital Sound Age. Indiana: Indiana University Press.

Kleege, G. (2018). More than Meets the Eye: What Blindness brings to art. New York: Oxford University Press.

Lopez, M. (2015). Perceptual evaluation of an audio film for visually impaired audiences. Audio Engineering Society 138th Convention, Warsaw, Poland.

Lopez, M., Kearney, G., \& Hofstädter, K. (2018). Audio description in the UK: What works, what doesn't, and understanding the need for personalising access. British Journal of Visual Impairment, 36(3), 274-291. https://doi.org/10.1177/0264619618794750

Lopez, M., Kearney, G. \& Hofstädter, K. (2020a). Seeing films through Sound: Sound design, spatial audio, and accessibility for visually impaired audiences. British Journal of Visual Impairment, 1-28, https://doi.org/10.1177/0264619620935935

Lopez, M., Kearney, G., Hofstädter, K. \& Balla, G. (2020b). Enhancing Audio Description: accessible filmmaking, sound design and the importance of educating filmmakers. Media Practice and Education, 1-16, https://doi.org/10.1080/25741136.2020.1832830

Lopez, M., \& Pauletto, S. (2009a). The design of an audio film for the visually impaired. Proceedings of the 15th International Conference on Auditory Display, Copenhagen, Denmark.

Lopez, M., \& Pauletto, S. (2009b). The design of an audio film: Portraying story, action and interaction through sound. The Journal of Music and Meaning, 8, 1-17.

Naraine, M. D., Fel,s D. I., \& Whitfield, M. (2018). Impacts on Quality: Enjoyment Factors in Blind and Low Vision Audience Entertainment ratings: A qualitative study. PLOS ONE, 13(12), 1-23. https://doi.org/10.1371/journal.pone.0208165

Palumbo, H. (Director). (2015) Pearl [Film]. University of York.

Rai, S., Greening, J., \& Petré, L. (2010). A Comparative Study of Audio Description Guidelines Prevalent in Different Countries. Media and Culture Department, Royal National Institute of Blind People.

Rattigan, D. (2002). Theatre of Sound: Radio and the Dramatic Imagination. Dublin: Carysfort Press. Romero-Fresco, P. (2013). Accessible Filmmaking: Joining the dots between audiovisual translation, accessibility and filmmaking. The Journal of Specialised Translation, 20, 201-223.

Romero-Fresco, P. \& Fryer, L. (2018). Accessible Filmmaking Guide. London: Archer's Mark.

Romero-Fresco, P. (2019). Accessible Filmmaking: Integrating translation and accessibility into the filmmaking process. Oxon: Routledge.

Schafer, M. (1994). The soundscape: our sonic environment and the tuning of the world. Rochester: Destiny Books.

Snyder, J. (2007). Audio Description: The Visual Made Verbal. The International Journal of the Arts in Society, 2. 
Story, M. F., Mueller, J. L. \& Mace, R. L. (1998). The Universal Design File: Designing for People of All Ages and Abilities. Raleigh, NC: North Carolina State University. Available at https://files.eric.ed.gov/fulltext/ED460554.pdf

Szarkowska, A. (2013). Auteur description: From the director's creative vision to audio description. Journal of Visual Impairment \& Blindness, 107, 383-387.

https://doi.org/10.1177/0145482X1310700507

Thompson, H. (2018). Audio Description: Turning Access to Film into Cinema Art. Disability Studies Quarterly, 38 (3).

Udo, J-P. \& Fels, D. I. (2010). The Rogue Poster-Children of Universal Design: Closed Captioning and Audio Description. Journal of Engineering Design, 21 (2-3), 207-221. https://doi.org/10.1080/09544820903310691

Walczak, A., \& Fryer, L. (2017). Creative description: The impact of audio description style on presence in visually impaired audiences. British Journal of Visual Impairment, 35, 6-17. https://doi.org/10.1177/0264619616661603

Whitfield, M., \& Fels, D. I. (2013). Inclusive design, audio description and diversity of theatre experiences. The Design Journal, 16(2), 219-238. https://doi.org/10.2752/175630613×13584367984983 